\title{
Inhibition of N-terminal ATPase on HSP90 attenuates colitis through enhanced Treg function
}

\author{
CB Collins ${ }^{1,2,3}$, CM Aherne $^{2,4}$, A Yeckes ${ }^{1,2,3}$, K Pound ${ }^{1,2,3}$, HK Eltzschig ${ }^{2,4}$, P Jedlicka ${ }^{5}$ and EF de Zoeten $^{1,2,3}$
}

Inflammatory bowel disease (IBD) is a chronic inflammatory condition thought to reflect a failure of the enteral immune system to adequately regulate itself. Inflammatory stress drives upregulation of heat-shock proteins (HSPs), including the pro-inflammatory chaperone, HSP90. This protein sequesters the transcription factor, heat-shock factor 1 (HSF1) in the cytoplasm preventing transcription of a number of anti-inflammatory proteins. We hypothesized that inhibition of HSP90 would exert an anti-inflammatory effect and thereby attenuate intestinal inflammation in murine models of IBD. Inhibition of HSP90 with 17-allylaminogeldanamycin (17-AAG) reduced inflammation in acute dextran sodium sulfate and chronic CD45RB ${ }^{\text {High }}$ colitis models coinciding with increased interleukin (IL)-10 production in the colon. Regulatory T cells (Tregs) from mice treated with 17-AAG demonstrated significantly greater suppressive capacity in vitro abolished in $\mathrm{HSF} 1^{-I^{-}}$or IL-10 ${ }^{-1-}$ cells. Finally, Tregs treated with 17-AAG exhibited increased nuclear localization of HSF1 with resultant upregulation of HSF1 response genes, including HSP70, HSP90 and IL-10.

\section{INTRODUCTION}

Constant exposure of the gut mucosa to luminal antigens makes regulation of the inflammatory response crucial to maintaining a state of hyporesponsiveness. Animal studies indicate that $\mathrm{CD} 4{ }^{+} \mathrm{CD} 25^{+} \mathrm{Foxp}^{+}{ }^{+}$regulatory $\mathrm{T}$ cells (Tregs) provide balance for the immune response in normal intestinal mucosa. ${ }^{1,2}$ A breakdown of this tolerance has a pivotal role in the development of inflammatory bowel disease (IBD). ${ }^{3}$ Both mice and humans with a defect in the forkhead box p3 (Foxp3) gene develop a wide range of autoimmune and inflammatory pathologies, including enteritis, providing evidence that this pathway may be relevant for intestinal homeostasis.

Previous studies using inhibitors of histone deacetylase (HDAC) to enhance Treg function and thereby attenuate murine colitis suggest a role for HDAC6-dependent regulation of heat-shock protein (HSP) $90 .{ }^{4}$ Inducible HSPs are activated under conditions of cellular stress; these stresses include chemical, heat, hypoxia, and exposure to cytokines. These proteins, once expressed, act as chaperones to either allow for normal protein folding or to stabilize the protein and prevent degradation. Transcriptional activation of the heat-shock response requires release of heat-shock factor 1 (HSF1) from its chaperone HSP90 and trimerization of HSF1. It has previously been demonstrated that HSF1 and HSPs are involved in the repression of pro-inflammatory cytokines such as interleukin (IL)-1 $\beta$, tumor-necrosis factor- $\alpha$ (TNF $\alpha$ ), interferon- $\gamma(\text { IFN } \gamma)^{5-7}$ and activation of the anti-inflammatory gene IL-10. ${ }^{8,9}$ In genome-wide association studies, HSF1 and HSPs have been associated with IBD, ${ }^{10,11}$ generally as protective factors.

Inhibitors of HSP90 such as 17-allylaminogeldanamycin (17-AAG) have been shown to compete with ATP for binding to the N-terminus of the protein, causing release of HSF1 from the inhibitory complex with HSP90, thus allowing trimerization of HSF1 and translocation to the nucleus. ${ }^{12}$ Nuclear HSF1 binds to heat-shock response elements and induces transcription of heat-shock response genes. ${ }^{13}$

HSP90 inhibitors have proven effective in treatment of murine models of sepsis, ${ }^{6}$ arthritis, ${ }^{14}$ uveitis, ${ }^{15}$ and multiple sclerosis, ${ }^{16}$ but their potential in IBD has yet to be established. Here we examined the therapeutic benefit of $17-\mathrm{AAG}$, a potent inhibitor of HSP90, for the regulation of inflammation in two distinct murine models of colitis. First, we investigated whether

\footnotetext{
${ }^{1}$ Department of Pediatrics, University of Colorado School of Medicine, Aurora, Colorado, USA. ${ }^{2}$ Mucosal Inflammation Program, University of Colorado School of Medicine, Aurora, Colorado, USA. ${ }^{3}$ Children's Hospital Colorado, Digestive Health Institute, Aurora, Colorado, USA. ${ }^{4}$ Department of Anesthesiology, University of Colorado School of Medicine, Aurora, Colorado, USA and ${ }^{5}$ Department of Pathology, Aurora, Colorado, USA. Correspondence: EF de Zoeten (Edwin.DeZoeten@childrenscolorado.org) 
inhibition of HSP90 affected colitis onset and severity. We next assessed if HSP90 inhibition could reverse established adoptive-transfer colitis. We then investigated the capacity of HSP90 inhibition to enhance Treg function ex vivo and thereby offer a Treg-dependent mechanism to modulate disease severity. Finally, we assessed the effect of HSP90 inhibition on nuclear translocation of HSF1 in activated Tregs and subsequent changes in gene transcription. Our data further define a role for the heat-shock response pathway (HSP90 and HSF1) in the maintenance of mucosal immune homeostasis.

\section{RESULTS}

\section{HSP90 inhibition attenuates chemically induced} acute murine colitis

In order to evaluate the role of HSP90 inhibition on chemically induced murine colitis 10-week-old wild-type mice were treated with HSP90 inhibitor 17-AAG or vehicle for 7 days while receiving DSS ad libitum in drinking water. Treatment with $17-$ AAG significantly attenuated weight loss $(P<0.05)$ in the DSS colitis model as measured by repeated measures analysis of variance (Figure 1a). This effect coincided with a decreased colon shortening, a surrogate marker of colitis, in 17 -AAG-treated mice $(51 \pm 2 \mathrm{~mm} ; P<0.05)$ compared with vehicle $(43 \pm 2 \mathrm{~mm}$; Figure 1b).

A pathologist who was blinded to the experimental conditions performed histological assessment of colitis, which identified a significant decrease in tissue injury from vehicletreated (5.8 \pm 1.1$)$ compared with $17-\mathrm{AAG}(2.6 \pm 0.4 ; P<0.01$; Figure 1c). Inflammation indices also decreased from vehicletreated (7.6 \pm 0.8$)$ compared with $17-\mathrm{AAG}(4.7 \pm 0.3$; $P<0.01$; Figure 1c). This reduction in tissue injury, loss of crypt architecture, and epithelial integrity along with the reduction in inflammatory infiltrate are depicted in the representative hematoxylin and eosin micrographs (Figure 1d).

\section{Increased anti-inflammatory cytokines and cells following HSP90 inhibition}

To better understand the underlying mechanism by which HSP90 inhibition ameliorates inflammation, cytokine expression analysis was performed on colonic explants from DSS colitic mice treated with or without 17-AAG. These studies corroborated the histological evidence of attenuated inflammation, demonstrating a significant reduction in a number of inflammatory cytokines. Release of IL-2 decreased from $22.8 \pm 1.2 \mathrm{pg} \mathrm{ml}^{-1}$ from vehicle-treated mice to $15.7 \pm$ $0.8 \mathrm{pg} \mathrm{ml}^{-1}$ from 17-AAG-treated mice $(P<0.001)$. IL-4 secretion decreased from $26.7 \pm 2.0 \mathrm{pg} \mathrm{ml}^{-1}$ from vehicletreated mice to $9.9 \pm 0.8 \mathrm{pg} \mathrm{ml}^{-1}$ from 17-AAG-treated mice $(P<0.001)$. IL-17 secretion decreased from $440.4 \pm$ $39.9 \mathrm{pg} \mathrm{ml}^{-1}$ from vehicle-treated mice to $30.6 \pm 4.2 \mathrm{pg} \mathrm{ml}^{-1}$ from 17-AAG-treated mice $(P<0.001)$. IFN $\gamma$ secretion decreased from $74.8 \pm 8.6 \mathrm{pg} \mathrm{ml}^{-1}$ from vehicle-treated mice to $38.2 \pm 3.9 \mathrm{pg} \mathrm{ml}^{-1}$ from 17-AAG-treated mice $(P<0.01)$. Expression of IL-10 was significantly increased by $17-\mathrm{AAG}$ administration with $445.6 \pm 44.4 \mathrm{pg} \mathrm{ml}^{-1}$ released from vehicle-treated mice to $1704 \pm 239.1 \mathrm{pg} \mathrm{ml}^{-1}$ in 17 -AAG-treated mice $(P<0.001)$, while release of $\mathrm{TNF} \alpha$ was unaltered (Figure 2a). Similarly, expression of IL-1 $\beta$ and IL-6 were also not significantly altered (not shown).

Cell populations were evaluated from both the DSS-treated groups to assess for the presence of $\mathrm{CD} 4{ }^{+} \mathrm{Foxp} 3^{+}$cells. Lymphocytes were isolated from the spleen, MLN, and LP and evaluated by flow cytometry. We noted that there was an increase in the percentage of $\mathrm{CD} 4{ }^{+}{ }^{\mathrm{Foxp}} 3^{+}$cells in the colonic LP of mice treated with $17-\mathrm{AAG}(16 \% \pm 2 ; P<0.05)$ compared with vehicle-treated mice $(10 \% \pm 0$; Figure $2 \mathbf{b})$. In addition, we noted a significant increase in the percentage of $\mathrm{CD} 4{ }^{+} \mathrm{Foxp} 3^{+}$ cells in the MLN of 17 -AAG-treated mice $(14 \% \pm 1 ; P<0.01)$ compared with vehicle-treated mice $(7 \% \pm 1$; Figure $2 \mathrm{c})$. In summary, 17-AAG had a protective effect on the severity of DSS-mediated colitis partly mediated by decreased inflammatory cytokine production and increased frequency of Tregs.

\section{Expression of HSP90 is increased during murine colitis}

We evaluated the expression of HSP90 following induction of murine colitis to determine whether it was regulated by inflammation. Western blot analysis demonstrated a significant increase in expression of HSP90 relative to $\beta$-actin control in colitic tissue $(1.5 \pm 0.02 ; P<0.05$; Figure $3 \mathbf{a}, \mathbf{b})$ compared with water-treated mice. This was consistent with immuno fluorescent assessment of HSP90 expression from colonic tissues of water control and DSS-treated mice. It demonstrates that in the absence of inflammation, HSP90 expression is largely restricted to the base of the crypts, whereas during colitis, expression is upregulated particularly at the mucosal surface (Figure 3c). Our data therefore suggests that there is an increase in HSP90 expression in response to DSS-induced epithelial injury and intestinal barrier disruption.

\section{Expression of HSP90 is enriched in murine regulatory T cells}

To determine whether HSP90 had a role in Treg function, the expression of HSP90 was analyzed in newly induced Tregs by intracellular flow cytometry. $\mathrm{CD} 4{ }^{+} \mathrm{CD} 25^{\mathrm{Neg}}$ cells were cultured for 3 days in the presence of TGF $\beta$ (transforming growth factor- $\beta$ ), resulting in a robust induction of Tregs. Expression analysis of cultured Tregs demonstrated an upregulation of HSP90 $\alpha$ following heat shock (MFI $958 \pm 73$ in CD3/ CD28-stimulated Tregs vs. MFI $2096 \pm 48$ in heat-shocked TGF $\beta$-treated Tregs; $P<0.001)$. These changes were not noted in Foxp $3^{\mathrm{Neg}}$ cells (Figure 4a). Similarly, expression of HSP90 $\beta$ was also upregulated on Tregs (544 \pm 159 vs. $1214 \pm 64$ ), whereas not significantly increased in non-Tregs. Thus, during heat shock or potentially inflammatory stress, both HSP90 isoforms are preferentially upregulated in Tregs.

Expression analysis of intracellular HSP90 $\alpha$ and HSP90 $\beta$ by flow cytometry from wild-type mice demonstrated that both HSP $90 \alpha$ and $\beta$ isoforms were significantly upregulated on $\mathrm{CD}_{4}{ }^{+} \mathrm{Foxp}^{+}{ }^{+}$Tregs compared with non-Tregs freshly isolated from the spleen, MLN, and colonic LP (Figure 4c). Furthermore, expression of both isoforms was greatest in the MLN followed by the LP and was significantly lower in the 

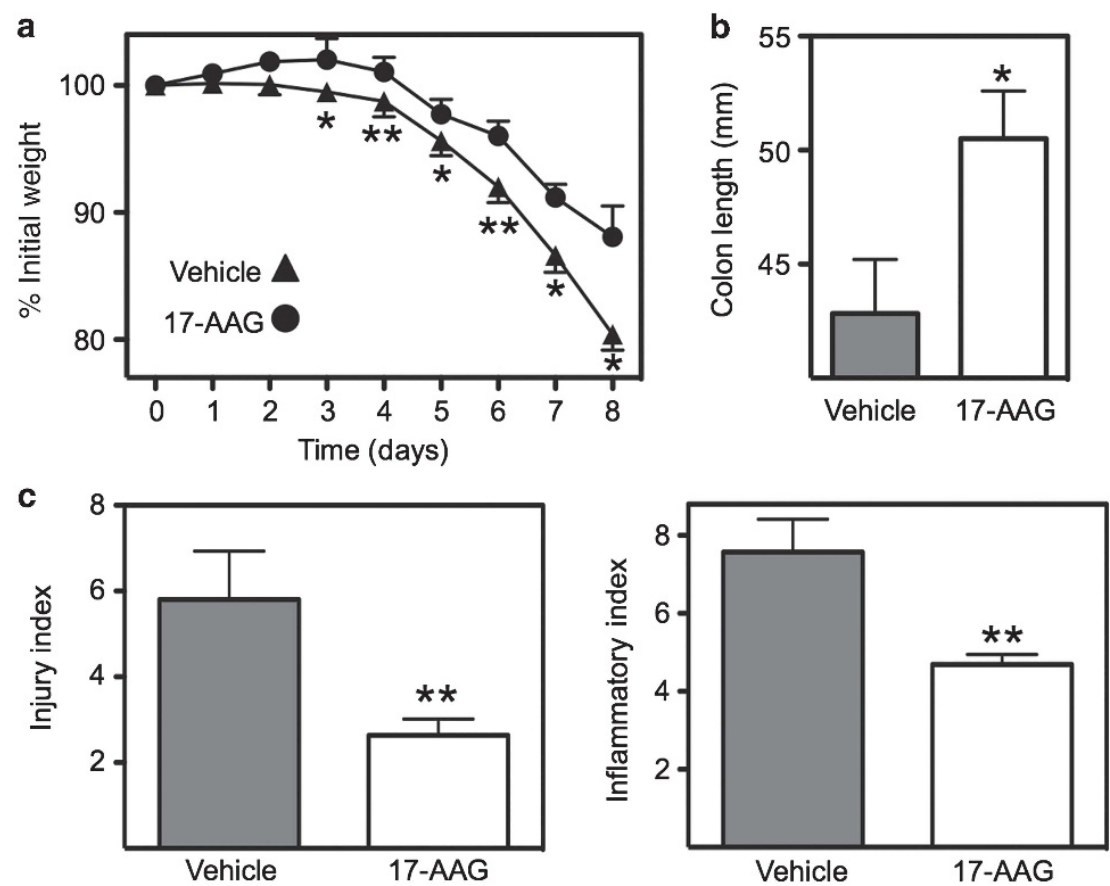

d

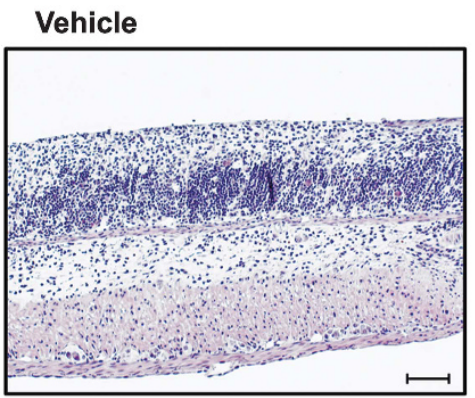

17-AAG

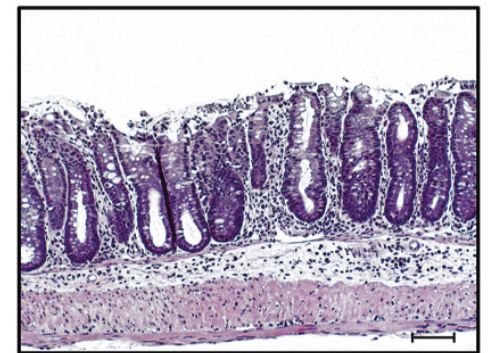

Figure 1 Heat-shock protein 90 inhibition attenuated chemically induced murine colitis. (a) Weight loss of mice treated with vehicle or 17allylaminogeldanamycin (17-AAG) during dextran sodium sulfate (DSS) colitis. Mean percentage of weight loss \pm s.e.m. from $n \geqslant 8$ mice, ${ }^{\star} P<0.05$, ${ }^{*} P<0.01$. (b) Colon length $(\mathrm{mm})$ of mice following DSS colitis measured postmortem, ${ }^{\star} P<0.05$. (c) Histological evaluation of indices of inflammation (injury and inflammation) by a trained pathologist (PJ) in a blinded fashion, ${ }^{\star \star} P<0.01$. (d) Representative micrographs of colonic hematoxylin and eosin sections from mice of each treatment group. Black scale bar indicates $100 \mu \mathrm{m}$.

spleen (Figure 4d). Thus, T-cell expression of HSP90 occurs preferentially on Tregs and appears to coincide with Treg activation.

\section{HSP90 inhibition alleviates colitis in the CD45RB ${ }^{\text {High }}$ adoptive-transfer model}

As DSS colitis is not predominantly T-cell mediated, we used the adoptive-transfer model of colitis to address the role of HSP90 in a more T-cell-directed manner. To do this, naïve $\mathrm{CD} 4{ }^{+} / \mathrm{CD} 45 \mathrm{RB}^{\mathrm{High}}$ cells were adoptively transferred into lymphopenic sex-matched recipients and development of colitis monitored indirectly by continuous assessment of body weight. 17-AAG-treated mice were protected from further significant weight loss and actually gained weight when treated with 17-AAG (101 $\pm 1 \% ; P<0.001$; Figure 5a) compared with vehicle-treated mice $(89 \pm 1 \%)$. Postmortem analysis revealed that 17 -AAG-treated mice $(71 \pm 4 \mathrm{~mm} ; P<0.01)$ displayed significantly less colonic shortening compared with the vehicle control mice ( $60 \pm 2 \mathrm{~mm}$; Figure $5 \mathbf{b})$. The protective effect of 17-AAG also resulted in a visible decrease in inflammation compared with vehicle controls. Active inflammatory indices decreased from vehicle-treated ( $7.8 \pm 1$; Figure $5 \mathbf{c})$ compared with 17 -AAG-treated mice $(2.6 \pm 1 ; P<0.01)$. Similarly, chronic inflammatory indices decreased from vehicletreated $(8.6 \pm 1)$ compared with 17-AAG-treated (4.6 \pm 1 ; $P<0.01)$. Furthermore, total inflammatory indices significantly decreased from vehicle $(16.4 \pm 1.5)$ compared with 17-AAG-treated mice $(7.2 \pm 1.4 ; P<0.001)$. Tissue from 17-AAG-treated mice also displayed significantly less disruption of crypt architecture as shown by representative hematoxylin and eosin micrographs (Figure 5d). This beneficial effect was lost when $\mathrm{CD}_{4} 5 \mathrm{RB}^{\mathrm{High}}$ adoptivetransfer colitis experiments were conducted using IL-10 ${ }^{-1-}$ cells consistent with a pivotal role for increased IL-10 production in the therapeutic effect of 17-AAG (see Supplementary Figure S1 online). 
a
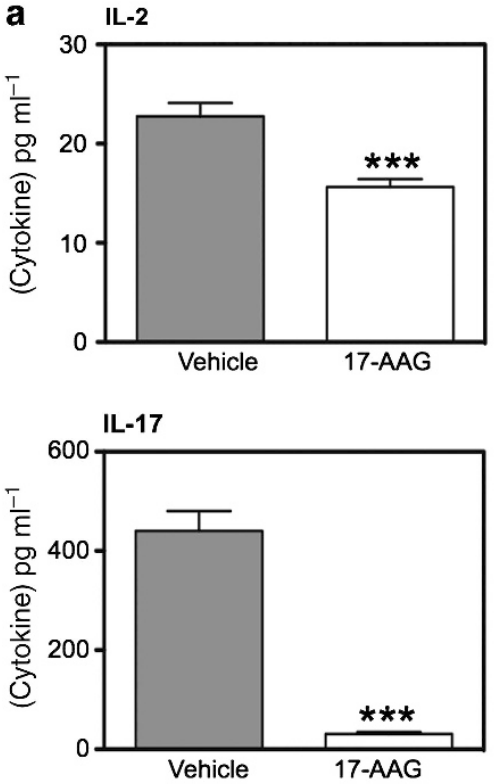

IL-4
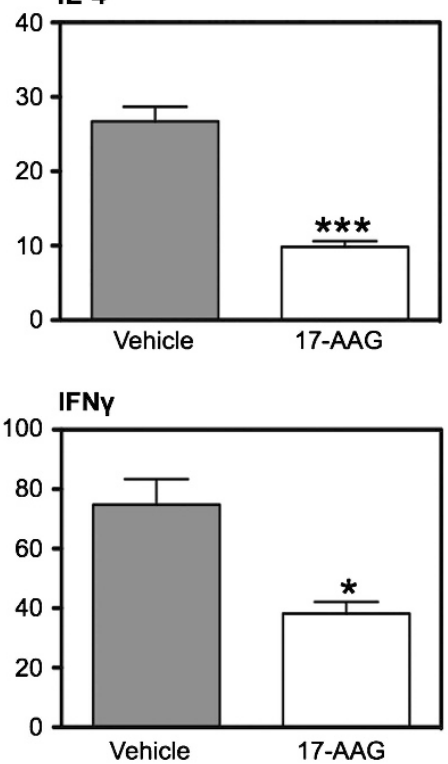

IL-10

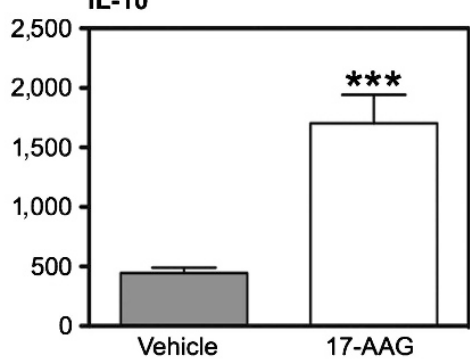

TNFa

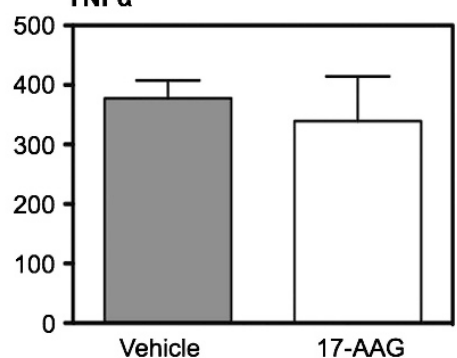

b

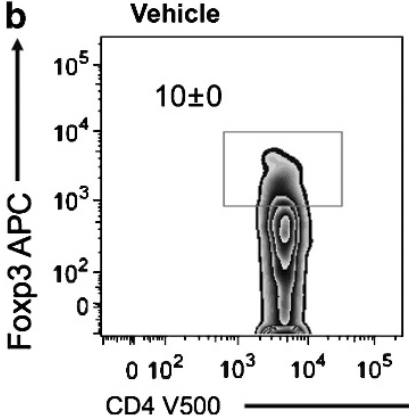

17-AAG

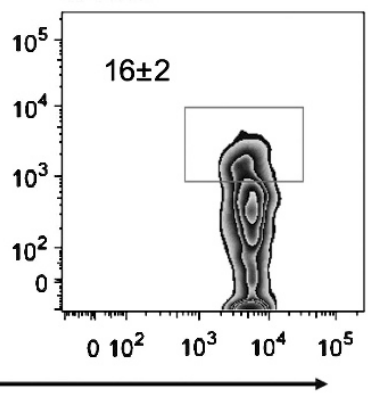

c

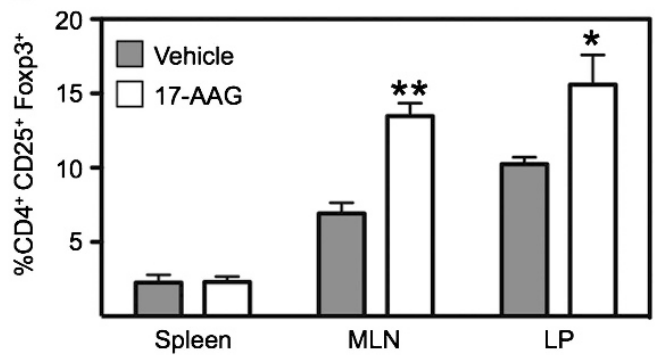

Figure 2 Altered cytokine profile from the inflamed colon following heat-shock protein 90 inhibition. (a) Multiplex analysis of interleukin (IL)-2, IL-4, IL-10, IL-17, interferon- $\gamma$ (IFN $\gamma$ ), and tumor-necrosis factor- $\alpha$ (TNF $\alpha$ ) expression from $24 \mathrm{~h}$ culture of colonic explants from dextran sodium sulfate (DSS) colitic mice treated with 17-allylaminogeldanamycin (17-AAG). Mean \pm s.e.m. for $n=4$ individual mice, ${ }^{\star} P<0.05,{ }^{* \star *} P<0.001$. (b) Representative zebra plot of CD4 T cells from the lamina propria (LP) of DSS colitic mice treated with vehicle or 17-AAG, showing expression of forkhead box p3 (Foxp3). (c) Percentage of $\mathrm{CD} 4{ }^{+} \mathrm{T}$ cells that are Foxp3 ${ }^{+}$from the indicated organs of colitic mice. Mean \pm s.e.m., $n=3,{ }^{*} P<0.05,{ }^{* \star} P<0.01$. APC, allophycocyanin; MLN, mesenteric lymph node.

\section{HSP90 inhibition promotes IL-10 production and Treg induction during chronic colitis}

To assess the impact of HSP90 inhibition on cytokine production in this T-cell-dependent colitis model, multiplex cytokine analyses were performed on cultured explant tissues as before. Cytokine expression analysis from $\mathrm{CD}_{4} 5 \mathrm{RB}^{\mathrm{High}}$ recipient mice demonstrated a similar pattern to those of DSS colitic mice, with a significant decrease in IFN $\gamma$ from vehicle-treated controls $\left(59 \pm 7 \mathrm{pg} \mathrm{ml}^{-1}\right)$ compared with 17 AAG-treated mice $\left(29 \pm 3 \mathrm{pg} \mathrm{ml}^{-1} ; \quad P<0.01\right.$; Figure 6a). Although TNF $\alpha$ production was higher from vehicle controls $\left(283 \pm 58 \mathrm{pg} \mathrm{ml}^{-1}\right)$ relative to 17 -AAG-treated mice $\left(156 \pm 35 \mathrm{pg} \mathrm{ml}^{-1}\right)$, this difference was not statistically significant. As in the DSS model, IL-10 production significantly increased from vehicle-treated mice $\left(19 \pm 2 \mathrm{pg} \mathrm{ml}^{-1}\right)$ to 17 AAG-treated mice $\left(168 \pm 27 \mathrm{pg} \mathrm{ml}^{-1} ; P<0.001\right)$. Therefore 17-AAG induced a similar pattern of cytokine production in CD45RB ${ }^{\text {High }}$ colitis as with DSS colitis, with $17-\mathrm{AAG}$-treated mice producing significantly more IL- 10 .

Thereafter, cell populations were evaluated from the above adoptive-transfer colitis experiments, and treated groups were assessed for the presence of $\mathrm{CD} 4{ }^{+} \mathrm{Foxp}^{+}$cells. Lymphocytes were isolated from the spleen, MLN, and colonic LP and evaluated by flow cytometry. Similar to our DSS experiments, we noted that there was an increase in the percentage of LP $\mathrm{CD} 4{ }^{+} \mathrm{Foxp}^{+}$cells from vehicle-treated mice $(3 \% \pm 0$; Figure $6 \mathbf{b})$ to mice treated with $17-\mathrm{AAG}(5 \% \pm 1 ; P<0.01)$. Moreover, we demonstrated a significant increase in IL-10 production by Tregs isolated from RAG1 ${ }^{-1-}$ colitic mice treated with 17-AAG $(18 \% \pm 1$; Figure 6d) compared with vehicle controls $(5 \% \pm 0 ; P<0.001)$. Therefore, 17 -AAG attenuated established colitis in this adoptive-transfer model and increased the presence of Tregs along with increasing their IL-10 production in the colonic LP. 

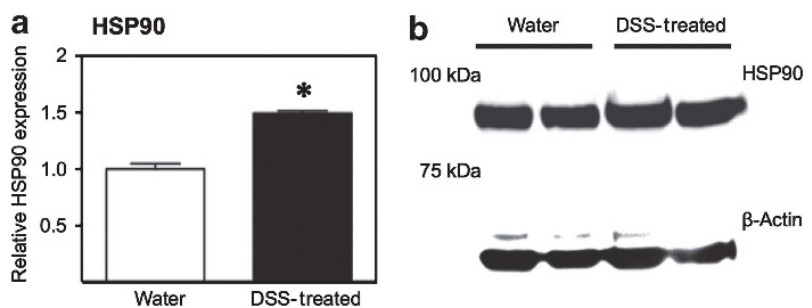

C
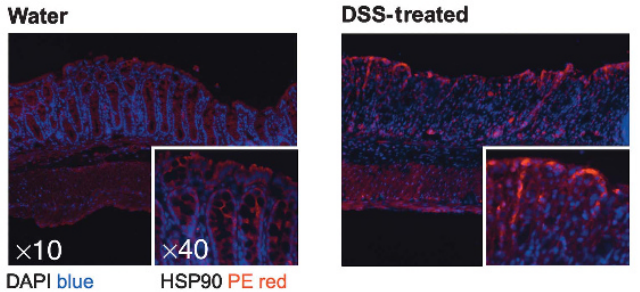

Figure 3 Protein expression and localization of heat-shock protein 90 (HSP90) in the inflamed mouse colon compared with untreated controls. (a) Densitometric determination of HSP90 expression in colonic tissue from water-treated or dextran sodium sulfate (DSS)-treated mice, ${ }^{\star} P<0.05$. (b) Representative western blot of HSP90 expression from water and DSS-treated mouse colonic homogenates. (c) Representative immunofluorescent micrographs showing staining for HSP9O in PE at $\times 10$ and $\times 40$ magnification at room temperature using a Zeiss Axio Imager A1 Microscope with Axiovision 4.6 acquisition software. DAPI, 4,6-diamidino-2-phenylindole; PE, phycoerythrin.

\section{Suppressive function of Tregs is increased by HSP90 inhibition via HSF1}

Above we have noted an increase in Treg numbers after treatment with 17-AAG as well as an increase in IL-10 expression in the two models of colitis. We next addressed the role of HSP90 inhibition in Treg function by analyzing proliferation of fluorescently labeled target cells in the presence of increasing ratios of Tregs. Co-culture of naive CellTracelabeled CD $25^{\mathrm{Neg}}$ Teffector cells with increasing concentrations of Tregs treated with 17-AAG demonstrated a significant decrease in proliferation in the 17-AAG-treated group. For example, at a 1:4 Treg:Teffector ratio, $30 \%$ of CellTrace-labeled cells proliferated compared with $37 \%$ proliferation in the $\mathrm{HSF}^{+/+}$control group (Figure 7). Whereas HSF1 ${ }^{-/}-$Tregs had comparable suppressive capacity as their $\mathrm{HSF} 1^{+1+}$ counterparts, lack of HSF1 abrogated the enhancement of suppressive function seen in 17-AAG-treated Tregs. Thus, 17AAG enhances Treg function in an HSF1-dependent manner.

To further define the mechanism of 17-AAG-mediated enhanced Treg suppression, we repeated the Treg-suppression assays using cells from IL-10 ${ }^{-1-}$ mice. As has been reported previously, IL-10 ${ }^{-/}$Tregs have decreased suppressive function; however, more importantly, the enhancement seen with 17-AAG was abolished in the absence of IL-10. Therefore, the HSF1-dependent 17-AAG-mediated increased suppression appears to be IL-10 dependent as well (Figure 8).

\section{Increased translocation of HSF1 in Tregs treated with 17-AAG}

With the loss of function of $17-\mathrm{AAG}$ in $\mathrm{HSF} 1^{-/-}$mice in the Treg assays and other data suggesting the role of HSP90 in regulation of HSF1 activation and translocation, we next assessed the role of inhibition of HSP90 on HSF1 translocation in the Treg cells. To address this, we performed western blot analysis of HSF1 expression in cytoplasmic and nuclear Treg fractions under both native and denatured conditions. This demonstrated an increased translocation of the HSF1 trimer to the nucleus of activated Tregs following $6 \mathrm{~h}$ stimulation with 17-AAG (250 nM; Figure 9a) compared with vehicle controls. This increase corresponded with an upregulation of HSP90aa1, HSPA1A, and IL- 10 at both $6 \mathrm{~h}$ and $24 \mathrm{~h}$ time-points, whereas HSP90ab1 was only induced at the early time-point and HSPA1B at the late time-point (Figure 9b). Thus, HSP90 inhibition with 17-AAG promotes translocation of HSF1 to the nucleus with resultant upregulation of HSF1 response genes.

\section{DISCUSSION}

The heat-shock response has a critical role in regulating new protein synthesis in response to cellular stress, including during the induction of an inflammatory response. In this study, we identify a role of the heat-shock response in mucosal homeostasis via Treg control. Considerable progress has been made in recent years in understanding the basic biology of HSPs and, in particular, HSP90 signaling during inflammation; however, little is known about their role in the induction/maintenance of chronic intestinal inflammatory conditions, such as IBD. As such, this study aimed to investigate the effect of HSP90 inhibition in both acute and chronic murine models of IBD. Of particular interest was whether pharmacological targeting of HSP90 might be of therapeutic value. In this series of studies, we demonstrate that HSP90 inhibition with 17-AAG, which binds to the N-terminal ATPase, ${ }^{17}$ attenuates both new-onset murine colitis using the DSS model and established colitis using the CD45RB ${ }^{\text {High }}$ adoptive-transfer model. Treatment with 17AAG enhanced secretion of anti-inflammatory IL-10, increased Treg numbers and improved efficiency of Treg suppression in an HSF1-dependent manner.

Having first identified a successful outcome with HSP90 blockade for the attenuation of colitis, we sought to better understand the expression of HSP90 in response to an inflammatory stimulus. HSP90 expression was increased in response to DSS colitis consistent with previous studies in human IBD demonstrating an upregulation of HSP90 and HSP70 associated with ulcerative colitis, which was decreased by treatment with 5 -aminosalicylic acid over 6 months. ${ }^{18}$ Although HSP90 is a ubiquitously expressed protein, ${ }^{19}$ we next sought to ascertain whether the upregulation of HSP90 was detectable in T cells. Flow cytometric analysis demonstrates that HSP90 isoforms are preferentially expressed on Foxp3 ${ }^{+}$ Tregs, and Treg induction in vitro drives expression of HSP90 particularly following heat shock. Moreover, expression of HSP90 in Tregs is greater on intestinal Tregs compared with splenic Tregs, consistent with it being key for intestinal immunity and upregulated upon Treg activation.

Based on these findings, we chose to focus on the therapeutic potential of 17-AAG in a T-cell-mediated colitis model using the $\mathrm{CD} 45 \mathrm{RB}^{\mathrm{High}}$ adoptive-transfer model ${ }^{20}$ of IBD. Consistent 

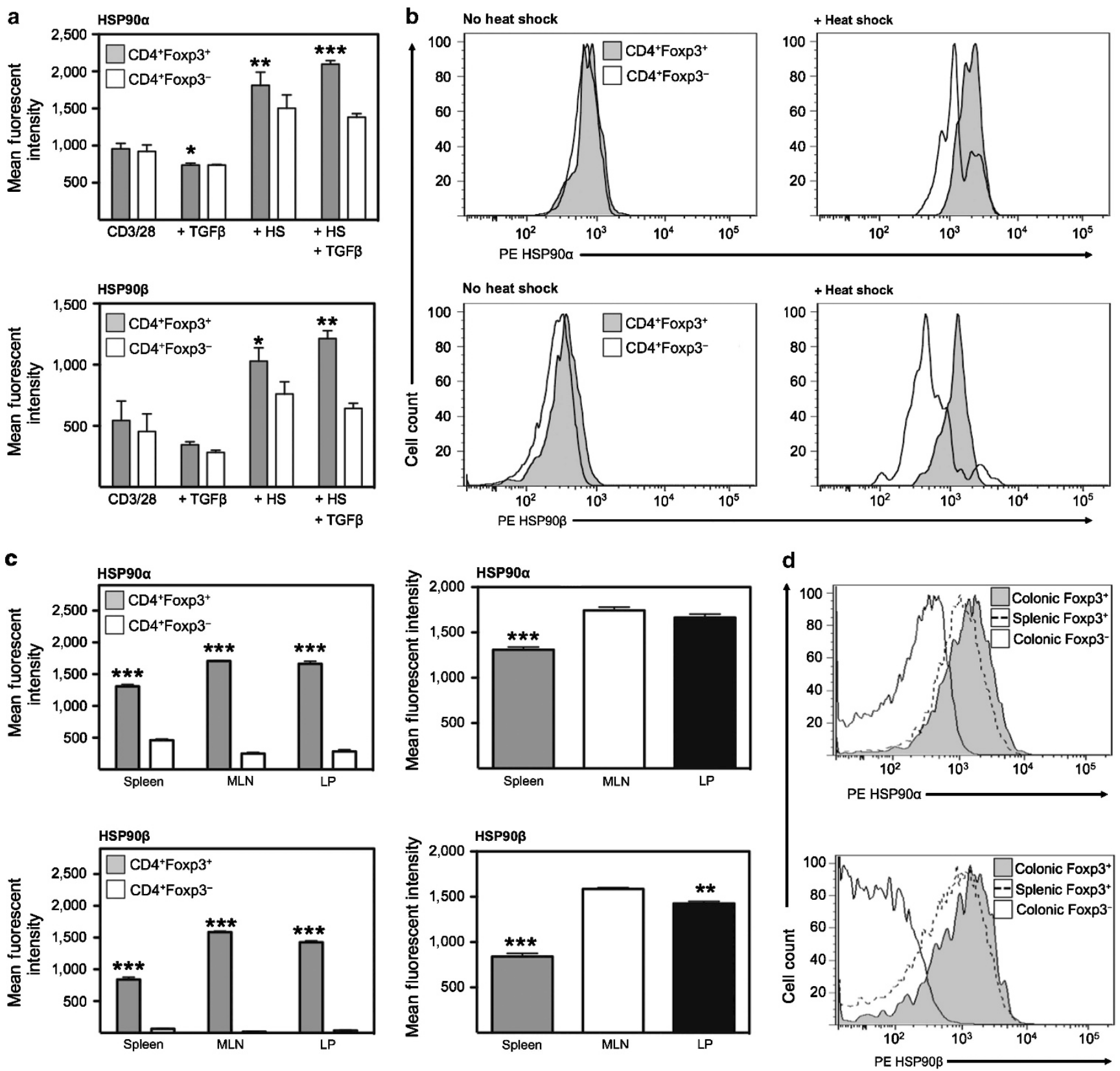

Figure 4 Heat-shock (HS)-induced HSP90 $\alpha$ (heat-shock protein $90 \alpha$ ) and HSP90 $\beta$ expression on mouse Tregs. (a) Mean fluorescent intensity of HSP90 $\alpha$ and HSP90 $\beta$ expression in permeabilized newly converted CD4 ${ }^{+} \mathrm{CD}_{25}{ }^{+}$Foxp3 ${ }^{+}$Tregs compared with non-Tregs with(out) heat shock. Mean \pm s.e.m., $n=3$, ${ }^{\star} P<0.05$, ${ }^{\star *} P<0.01$, ${ }^{\star \star \star} P<0.001$. (b) Representative histograms of expression of HSP90 $\alpha$ and HSP90 $\beta$ on permeabilized $\mathrm{CD}^{+}{ }^{+} \mathrm{Foxp}^{+}$(gray) or CD4 ${ }^{+}$Foxp3 ${ }^{\mathrm{Neg}}$ cells (white). (c) Mean fluorescent intensity of HSP90 $\alpha$ and HSP90 $\beta$ expression in permeabilized newly converted $\mathrm{CD} 4{ }^{+} \mathrm{CD} 25^{+}$Foxp3 ${ }^{+}$Tregs compared with non-Tregs with(out) heat shock. Mean \pm s.e.m., $n=3,{ }^{* *} P<0.01,{ }^{* * *} P<0.001$. (d) Representative histograms of expression of HSP90 $\alpha$ and HSP90 $\beta$ on permeabilized $\mathrm{CD} 4{ }^{+} \mathrm{Foxp}^{+}$from the colonic lamina propria (LP; gray), the spleen (dashed line) or $\mathrm{CD} 4{ }^{+}$Foxp $3^{\text {Neg }}$ cells (white). MLN, mesenteric lymph node; PE, phycoerythrin; TGF $\beta$, transforming growth factor- $\beta$.

with our previous findings, we observed an attenuation of inflammation in this model as well. Furthermore 17-AAG once again increased IL-10 production by Tregs along with Treg numbers while attenuating inflammation, pro-inflammatory cytokine secretion, and inflammatory cell infiltration into the colon. The increased expression of IL-10 may be sufficient to account for all of these observations as IL-10 has been shown previously to act as a growth factor for Tregs, ${ }^{21}$ and Tregderived IL-10 is critical for attenuation of colitis in this model. ${ }^{22}$
Similarly, we have observed a beneficial effect of increasing Treg frequency in IBD models previously. ${ }^{23}$ Furthermore, in the absence of T-cell-derived IL-10, 17-AAG was unable to rescue the colitis in this model, consistent with this being a primary therapeutic mechanism of action.

Our lab has previously demonstrated that 17-AAG enhances Tregs suppressive function in vitro; ${ }^{4}$ however, no mechanism of this enhancement was identified. Accurately identifying which protein chaperoned by HSP90 is altered in response to 17-AAG 

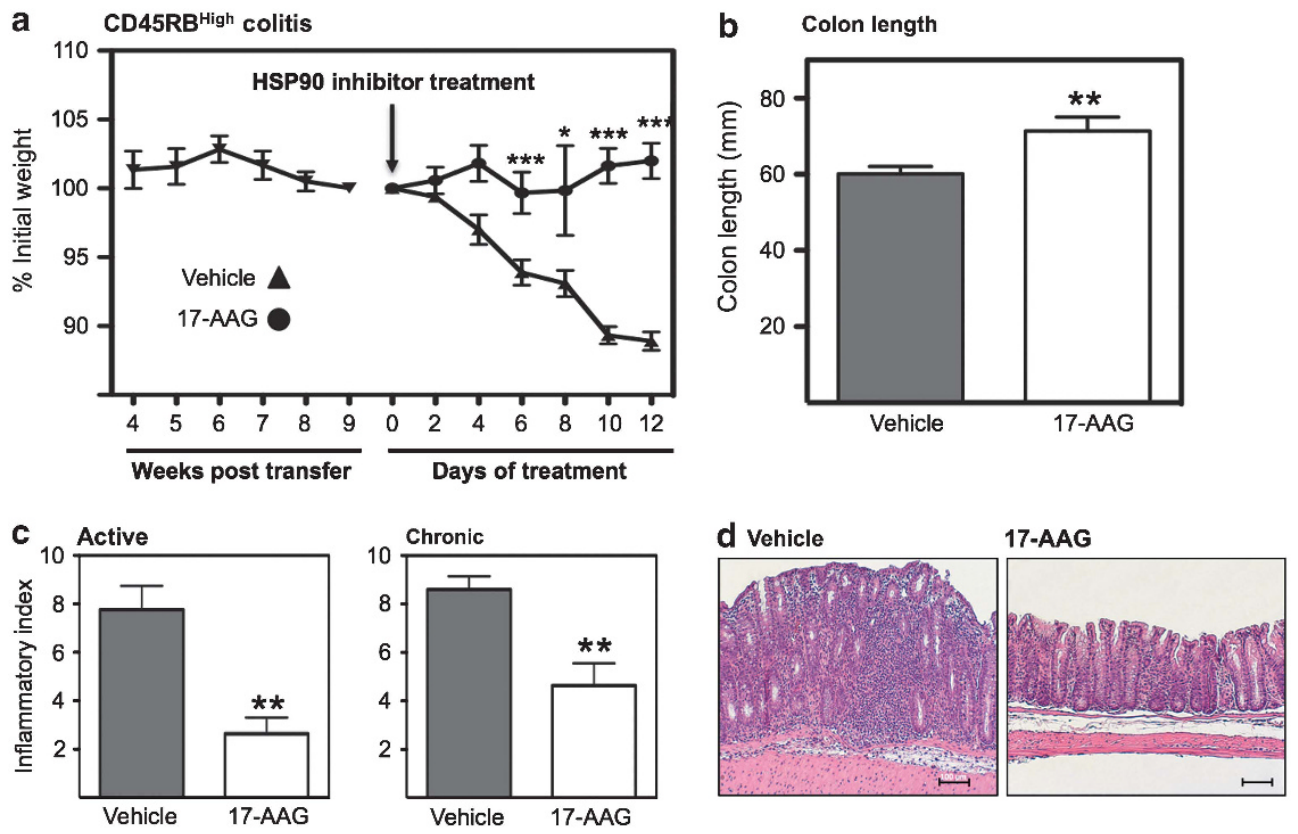

Figure 5 Heat-shock protein 90 (HSP90) inhibition attenuates established adoptive-transfer colitis. (a) Weight-loss curve of RAG1 ${ }^{-/-}$mice adoptively transferred $\mathrm{CD} 45 \mathrm{RB}^{\text {High }}$ cells treated with vehicle or 17 -allylaminogeldanamycin (17-AAG) upon establishment of disease, ${ }^{\star} P<0.05$,

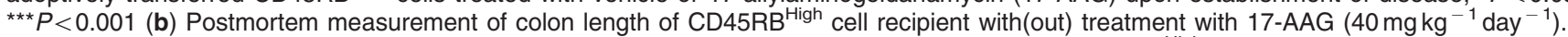
Mean \pm s.e.m., ${ }^{\star \star} P<0.01$. (c) Histological evaluation of indices of active and chronic inflammation in CD45RB High model of colitis by a trained pathologist in a blinded fashion. ${ }^{\star *} P<0.01$. (d) Representative micrographs of colonic hematoxylin and eosin sections from mice of each treatment group. Black scale bar indicates $100 \mu \mathrm{m}$.

is difficult, as there are currently over 100 known client proteins for HSP90. ${ }^{24}$ However, HSP90 does form a complex with HSP70, and HSP70 has been shown to attenuate murine arthritis via enhanced IL-10 production from Tregs so it is possible that inhibition of HSP90 increases the availability of HSP70, which then, in turn, enhances Treg function. ${ }^{25}$ Furthermore 17-AAG upregulates expression of HSP70 mRNA $^{26}$ and overexpression of HSP70 has been shown to enhance Treg-suppressive function. ${ }^{27}$ However, the ability of 17-AAG to drive HSP70 is actually HSF1-dependent, ${ }^{28}$ and so we sought to determine if the enhanced suppressive function might also be HSF1 dependent.

Using $\mathrm{HSF}^{-1-}$ cells, we demonstrated that enhanced suppressive function due to 17-AAG was abolished in the absence of $\mathrm{HSF}^{-1-}$. Pre-induction of the heat-shock response has been demonstrated previously to protect against acute murine colitis. ${ }^{29}$ Although not identified at the time, the anti-inflammatory effect of heat shock is likely mediated by induction of the transcription factor HSF $1 .{ }^{30} \mathrm{HSF} 1$ is known to drive expression of a number of anti-inflammatory genes, including IL-10 ${ }^{31}$ and HSP70, ${ }^{32}$ while also suppressing albeit transiently pro-inflammatory gene expression, including IL- $1 \beta$ and TNF $\alpha .{ }^{33}$ HSP90 also forms an inhibitory complex with HSF1, preventing trimerization, nuclear translocation, and transcriptional activation by HSF $1 .^{30}$ Inhibition of HSP 90 therefore disrupts that complex, increasing HSF1 translocation to the nucleus and enhancing HSF1 transcriptional activation function. ${ }^{12}$ This, in turn, acts as a negative regulator of proinflammatory cytokine gene transcription ${ }^{34}$ and a positive signal for anti-inflammatory gene transcription. Therefore, it is likely that the anti-inflammatory effects of HSP90 inhibitors are, at least, partly mediated via release of HSF1. The expression of HSP90 is induced in response to heat shock or inflammatory stress $^{29}$ via STAT1 (signal transducer and activator of transcription factor 1)-dependent induction, ${ }^{35}$ which may reflect a mechanism for limiting HSF1 activation. Pharmacological blockade of this endogenous braking mechanism may have therapeutic potential in overactive inflammatory diseases such as IBD, and indeed this has been borne out in other models of inflammation. Indeed, blockade of HSP90 has proven effective at attenuating inflammation in a number of autoimmune murine models via decreased expression of proinflammatory cytokines such as IL- $1 \beta^{15,16,36}$ consistent with the anti-inflammatory effects seen in our studies.

Having demonstrated that the effect of 17-AAG on Treg suppression was HSF1-dependent, we then extended these observations even further to demonstrate that it was also mediated via increased IL-10 output as IL-10 $0^{-1-}$ cells failed to display this enhanced suppressive function. These in vitro results are further supported by the suppression of adoptively transferred T-cell proliferation in CD45RB ${ }^{\text {High }}$ colitis. Furthermore, this is consistent with studies demonstrating enhanced Treg function in $\mathrm{HDAC6}^{-1-}$ mice, ${ }^{4}$ coinciding with increased HSP90 acetylation correlated with impaired HSP90 function. ${ }^{37}$ Based on our hypothesis that HSP90 inhibition with 17-AAG was driving IL-10 expression in a HSF1-dependent manner, we assessed the localization of HSF1 in activated Tregs treated with 17-AAG in vitro and demonstrated that, indeed, blockade of HSP90 caused a shift in HSF1 trimer to the nucleus and a subsequent mRNA upregulation of anti-inflammatory IL-10 

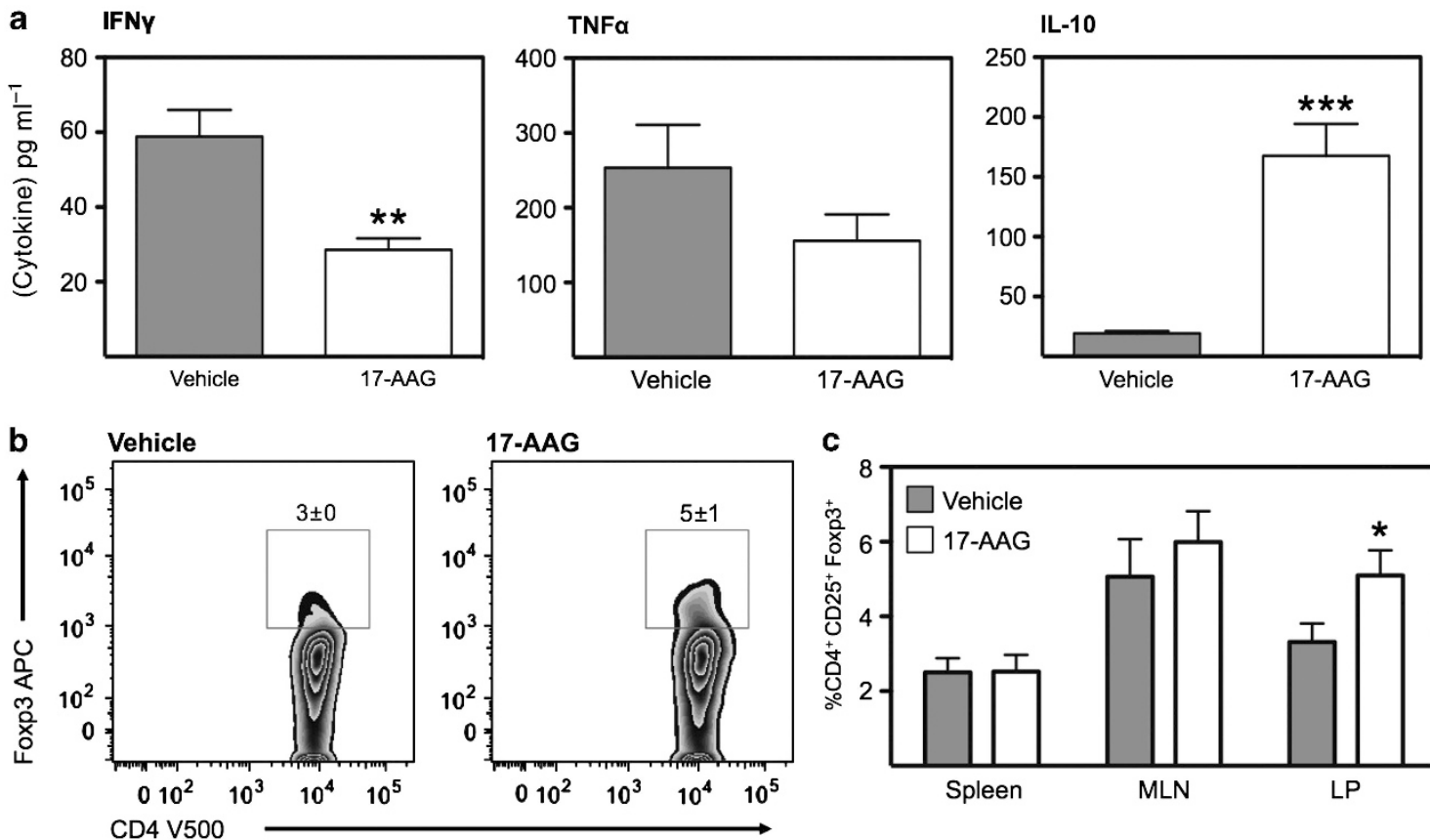

C
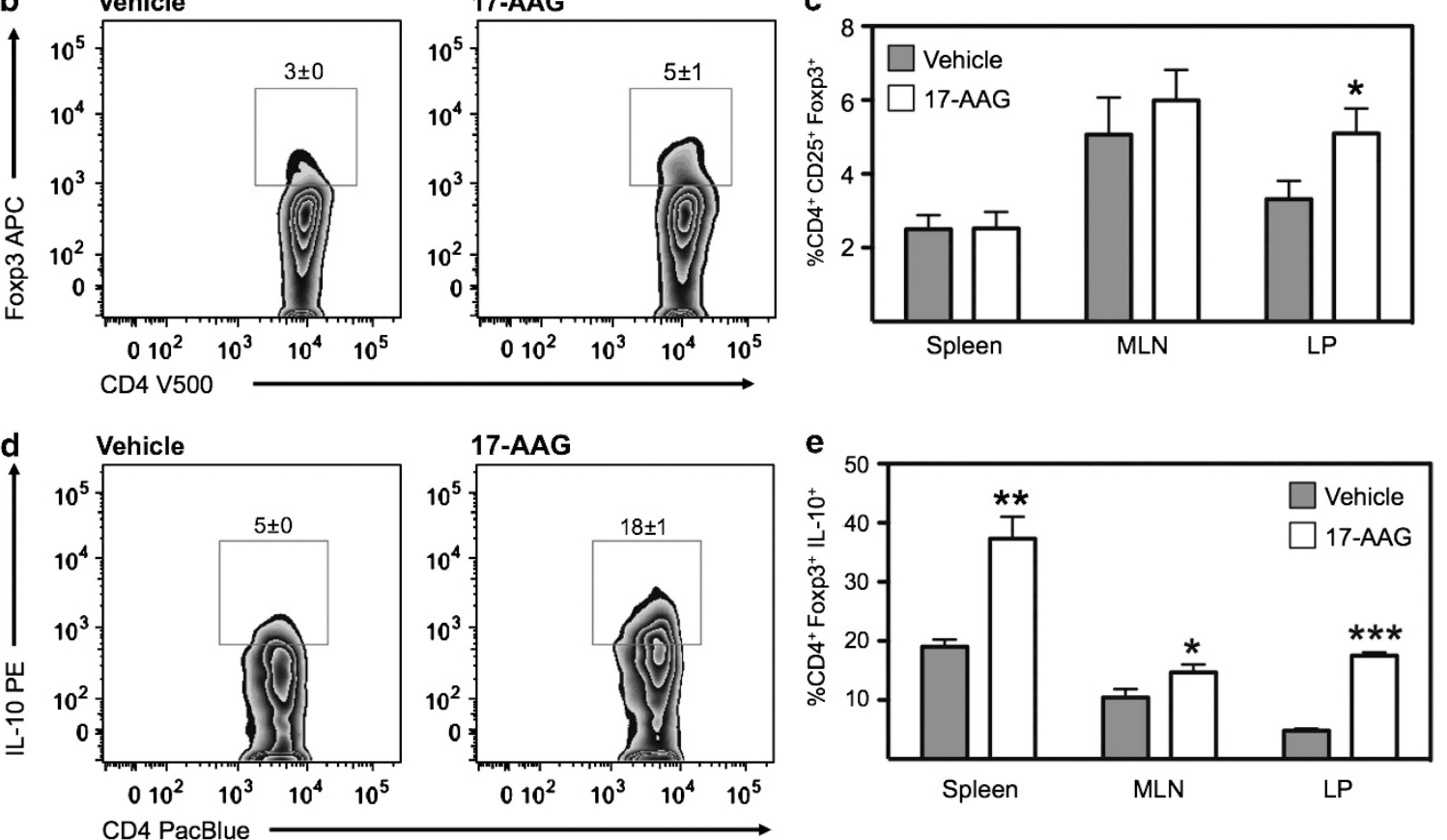

Figure 6 Heat-shock protein 90 (HSP90) inhibition increases interleukin (IL)-10 production and forkhead box p3 (Foxp3) expression in the inflamed colon. (a) Multiplex analysis of interferon- $\gamma$ (IFN $\gamma$ ), tumor-necrosis factor- $\alpha$ (TNF $\alpha$ ) and IL-10 expression from $24 \mathrm{~h}$ culture of colonic explants from CD45RB ${ }^{\text {High }}$ adoptive-transfer colitic mice treated with 17-allylaminogeldanamycin (17-AAG). Mean \pm s.e.m. for $n=4$ individual mice, ${ }^{\star \star} P<0.01$, ${ }^{* * *} P<0.001$. (b) Representative zebra plot of CD4 ${ }^{+}$T cells from the lamina propria (LP) of CD45RB ${ }^{\text {High }}$ colitic mice treated with vehicle or $17-A A G$, showing expression of Foxp3. (c) Percentage of CD4 ${ }^{+}$T cells that are Foxp3 ${ }^{+}$from indicated organs of colitic mice, ${ }^{\star} P<0.05$. (d) Representative zebra plots of IL-10 expression in CD4 ${ }^{+}$Foxp3 ${ }^{+}$regulatory T cells (Tregs) isolated from the colonic LP of CD45RB ${ }^{\text {Hgh }}$ colitis. (e) Percentage of CD4 ${ }^{+}$Foxp3 ${ }^{+}$ $\mathrm{IL}-10^{+}$Tregs following vehicle or $17-\mathrm{AAG}\left(40 \mathrm{mg} \mathrm{kg}^{-1}\right.$ day $\left.^{-1}\right)$ treatment. Mean \pm s.e.m., $n \geqslant 4,{ }^{\star} P<0.05,{ }^{\star \star} P<0.01$, ${ }^{\star \star *} P<0.001$. APC, allophycocyanin; MLN, mesenteric lymph node; PE, phycoerythrin.

and HSP70 isoforms (HSPA1A and HSPA1B) in isolated Tregs. These findings account for the enhanced suppressive function of Tregs treated with 17-AAG as well as the anti-inflammatory effect of 17-AAG in both IBD models tested. Interestingly, however, enhanced translocation of HSF1 to the nucleus also led to upregulation of HSP90 $\alpha$ and HSP90 $\beta$ mRNA. We believe that this response is part of a negative feedback autoregulatory mechanism whereby HSF1 upregulated HSP90, which, in turn, sequesters HSF1 in the cytoplasm to prevent overactivation/ translocation of the HSF1 anti-inflammatory pathway and thereby reduce risk of opportunistic infection associated with excessive immunosuppression.

The ability of HSP90 inhibition to attenuate murine colitis makes them an attractive candidate for future clinical application in IBD. The ongoing trials of HSP90 inhibitors in cancer chemotherapy in which their safety and pharmacokinetics are firmly established further support the translation of this technology to an IBD context. Finally, as we increase our understanding of the anti-inflammatory mechanisms of HSP90 inhibition in murine models of IBD, these data provide proof of principle for the application of newer more effective HSP90 inhibitors currently in development to use in the treatment of IBD.

\section{METHODS}

Mice. A colony of C57/B16J mice were maintained in house kept under specific pathogen-free conditions. Foxp3-green fluorescent protein, RAG1 ${ }^{-1-}$ (2216), IL-10 ${ }^{-1-}$ (2251), and HSF1 ${ }^{-/-}$mice (129/SvEvTac; 10543) were obtained from Jackson laboratories (Bar Harbor, ME); HSF $1^{+1+}$ littermates were used as controls for 
HSF $^{+/+}$

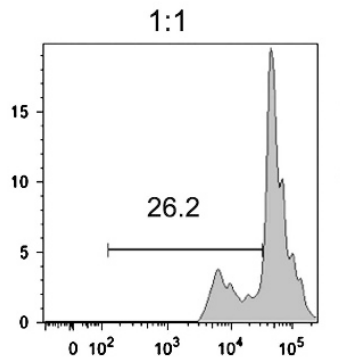

1:2

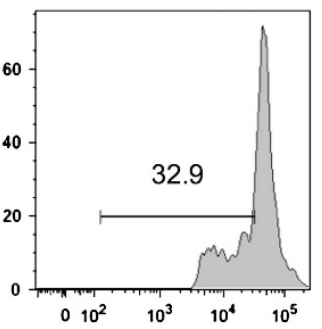

1:4

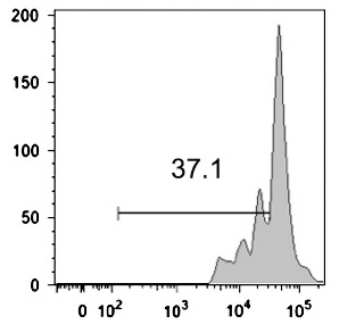

1:8

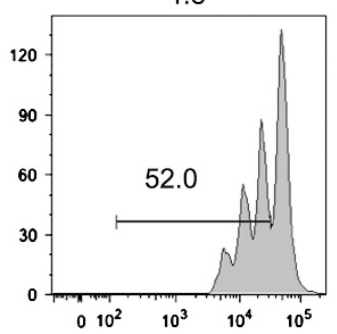

$0: 1$

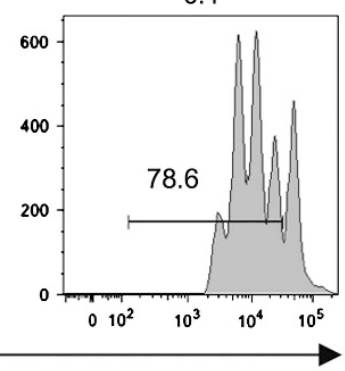

$\mathrm{HSF1}^{+/+}+17-\mathrm{AAG}$

1:1

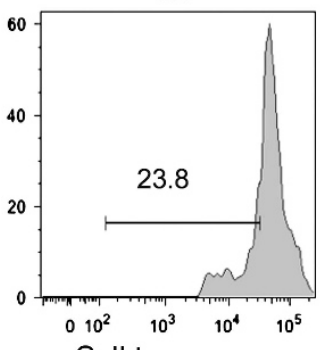

Cell trace
$1: 2$

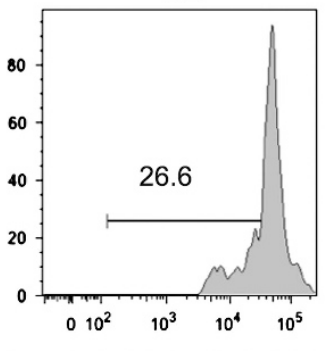

1:4

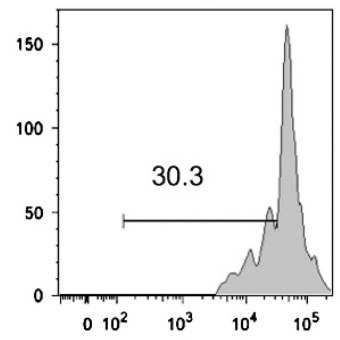

$1: 8$

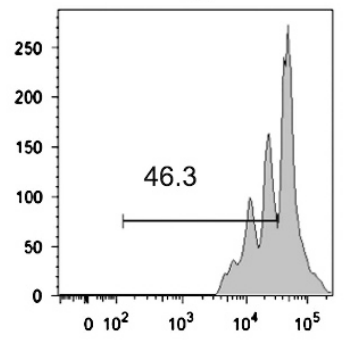

0:1

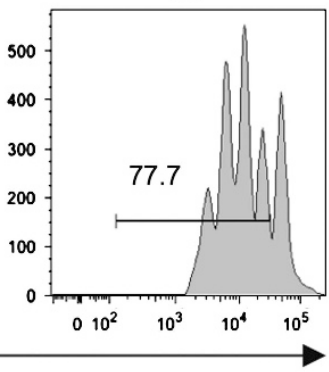

\section{HSF1-l- Tregs + 17-AAG}

1:1

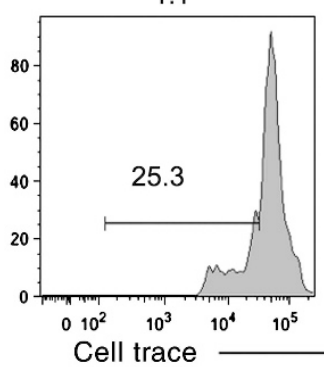

$1: 2$

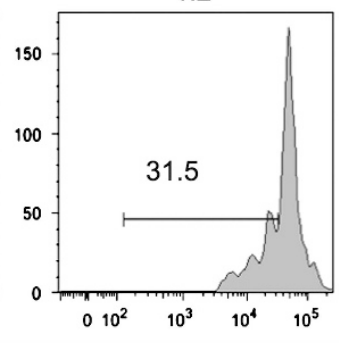

$1: 4$

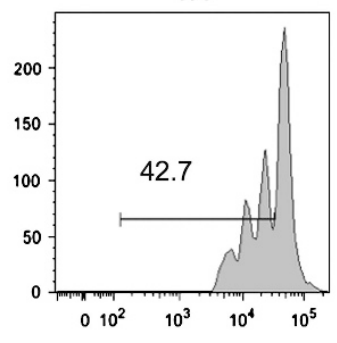

1:8

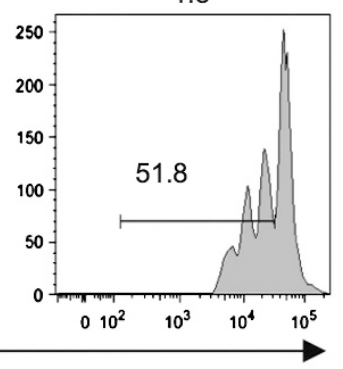

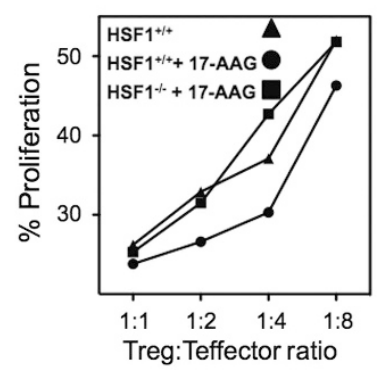

Figure 7 Heat-shock protein 90 (HSP90) inhibition enhances regulatory T cell (Treg) function in vitro via heat-shock factor 1 (HSF1). Representative histograms of CellTrace-labeled CD4 ${ }^{+} \mathrm{T}$ cells co-cultured with decreasing concentrations of $\mathrm{CD} 44^{+} \mathrm{CD} 25^{+} \mathrm{Tregs}$ from $\mathrm{HSF} 1^{+/+}$vehicle-treated

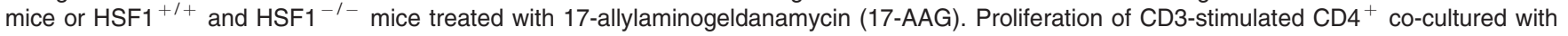
Tregs from vehicle or 17-AAG-treated mice. Results representative of $n=3$ individual experiments with similar results.

HSF1 ${ }^{-1-}$ mice. Fecal samples from these mice were consistently negative for Helicobacter, protozoa, and helminthes. All animals were handled according to the procedures approved by the institutional committee for animal use.

Chemically induced acute murine colitis model. Mice were treated with dextran sodium sulfate (DSS) ad libitum (3\% w/v; MP Biomedicals, Santa Ana, CA; 36-50 kDa) in drinking water for $7 \mathrm{~d}$. Water alone groups were included as a control. DSS groups received daily intraperitoneal injections of $17-\mathrm{AAG}\left(40 \mathrm{mg} \mathrm{kg}^{-1}\right)$ or vehicle dimethyl sulfoxide. Body weight, stool consistency, and occult bleeding were assessed daily to construct a disease activity index. At the time of killing, spleen, mesenteric lymph nodes (MLNs), and segments of colonic tissue were excised for flow cytometric analysis of leukocyte subsets, colon lengths were assessed and colon sections processed for histology, RNA extraction and cytokine analyses to assess disease activity. Histology was evaluated and scored by a trained pathologist blinded to the conditions of the experiments (PJ) according to a previously described scoring system. ${ }^{38}$ Colonic tissues were snap frozen and homogenized in RIPA buffer or paraffin embedded for western blot and immunofluorescence, respectively, using anti-HSP90 antibody (C45G5; Cell Signaling; Danvers, MA) according to the manufacturers instructions.

Adoptive-transfer murine colitis model. Naive T cells from Foxp3green fluorescent protein or IL-10 ${ }^{-1-}$ donor mice were isolated by magnetic enrichment of $\mathrm{CD} 4{ }^{+}$cells from splenocytes (CD4 T cell isolation kit, Miltenyi Biotec, Auburn, CA) followed by fluorescenceactivated sorting of $\mathrm{CD} 4{ }^{+} \mathrm{CD} 45 \mathrm{RB}^{\mathrm{High}} \mathrm{Foxp} 3^{\mathrm{Neg}}$ naive $\mathrm{T}$ cells. $\mathrm{RAG}^{-1-}$ mice received $5 \times 10^{5}$ naive $\mathrm{T}$ cells by intraperitoneal injection. Establishment of colitis was determined by weekly weight monitoring. Upon establishment of disease, mice were treated with 17-AAG (40 $\mathrm{mg} \mathrm{kg}^{-1}$ ) or vehicle (dimethyl sulfoxide), receiving daily injections for 10-12 days.

Lymphocyte isolation. Single-cell suspensions were obtained by gently pressing the MLN or spleen against a $70-\mu \mathrm{m}$ cell strainer. Splenic red blood cells were lysed by $3 \mathrm{~min}$ incubation in ammonium chloride lysing reagent (ACK Lysis Buffer, Invitrogen, Carlsbad, CA). Intestinal segments were opened along the mesentery and rinsed of luminal contents with phosphate-buffered saline before cutting into 


\section{IL-10-1- Tregs}
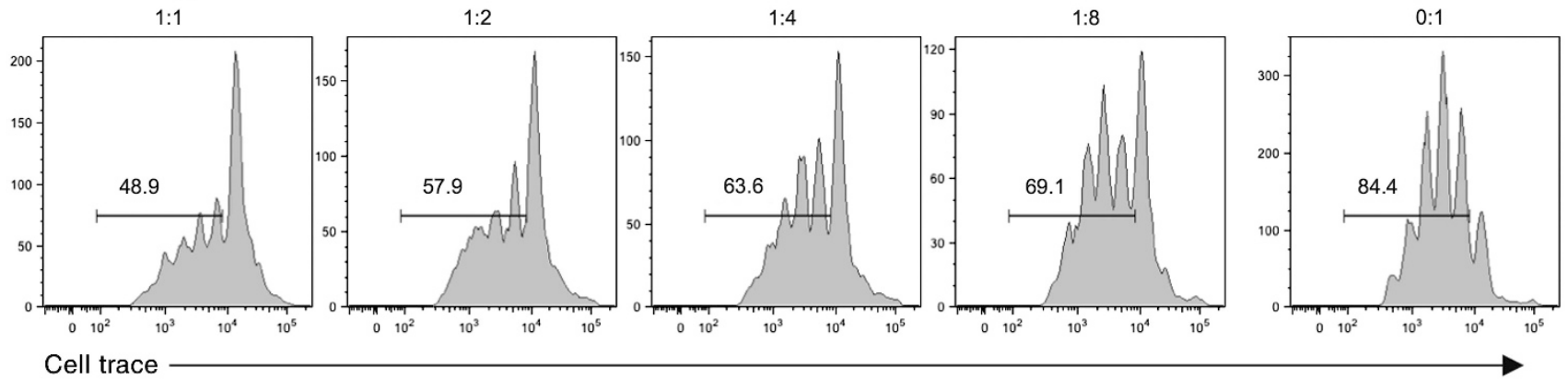

Cell trace

\section{$\mathrm{IL}-10^{-1-}+17-\mathrm{AAG}$}
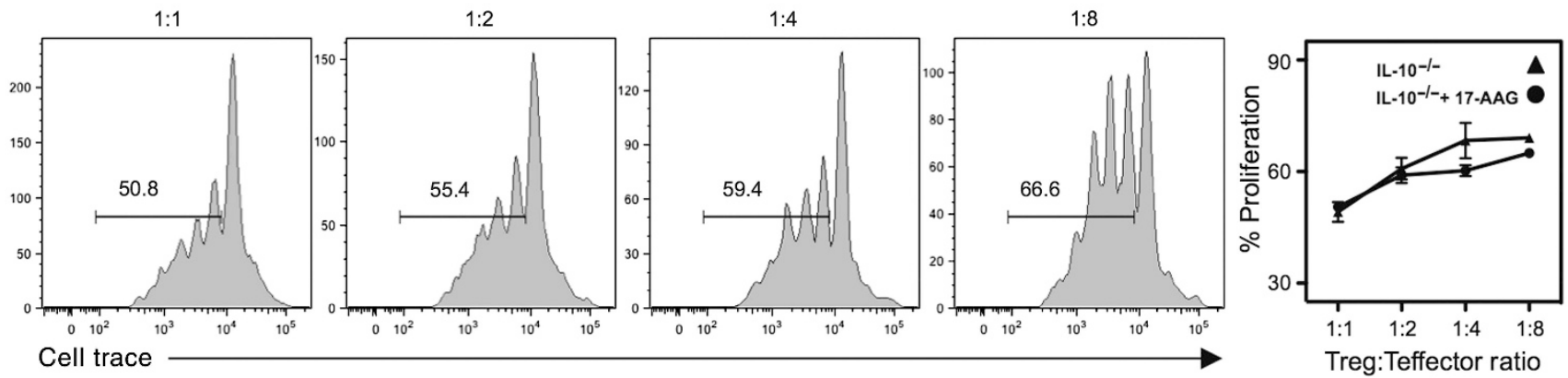

Figure 8 Enhancing suppressive function of 17-allylaminogeldanamycin (17-AAG) is interleukin (IL)-10 dependent. Representative histograms of CellTrace-labeled CD4 ${ }^{+}$T cells co-cultured with decreasing concentrations of CD4 ${ }^{+} \mathrm{CD} 25^{+}$regulatory $\mathrm{T}$ cells (Tregs) from IL-10 ${ }^{-1-}$ mice treated with(out) 17-AAG. Results representative of $n=3$ individual experiments with similar results.

a

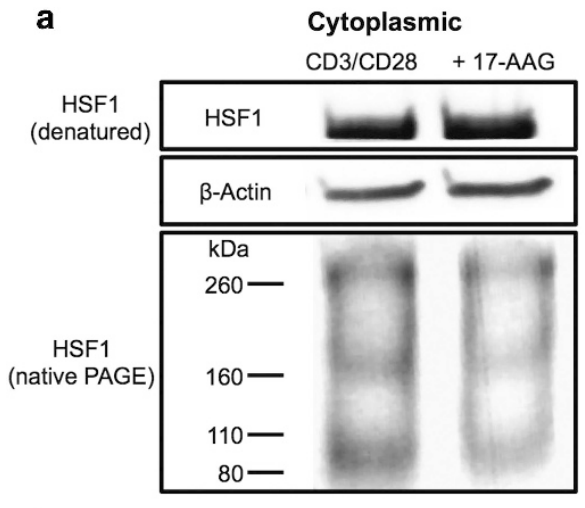

b

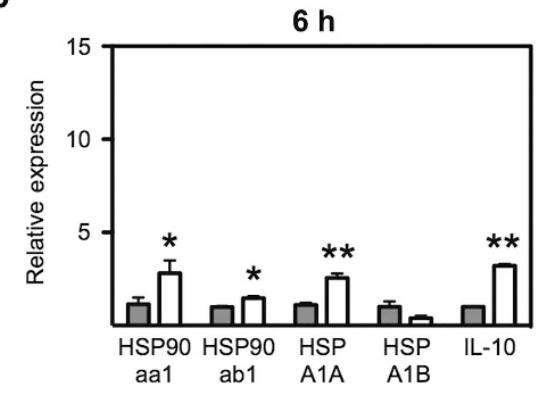

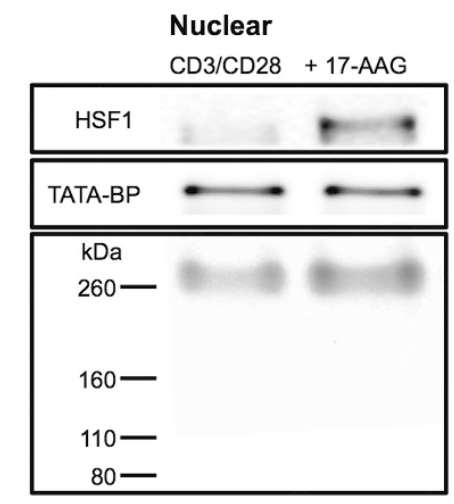

$24 \mathrm{~h}$

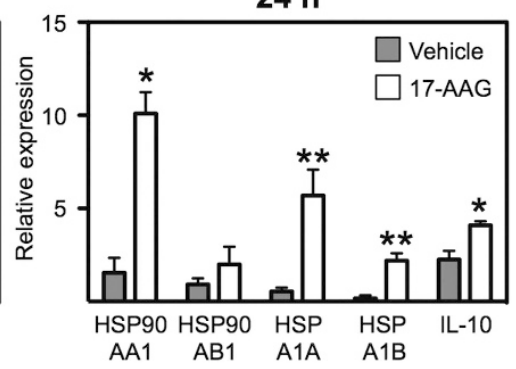

Figure 9 Heat-shock protein 90 (HSP90) inhibition increases heat-shock factor 1 (HSF1) translocation and transcriptional activation. (a) Representative blot of HSF1 either denatured or non-denatured from regulatory T cells (Tregs) stimulated for $6 \mathrm{~h}$ with CD3 and CD28 with(out) 17-allylaminogeldanamycin (17-AAG; $250 \mathrm{nm).} \mathrm{(b)} \mathrm{Realtime} \mathrm{reverse} \mathrm{transcriptase-PCR} \mathrm{analysis} \mathrm{of} \mathrm{expression} \mathrm{of} \mathrm{HSP90} \mathrm{isoforms} \mathrm{(aa1,} \mathrm{ab1),}$ HSP70 isoforms (HSPA1A, HSPA1B) and interleukin (IL)-10 mRNA from isolated activated Tregs treated for 6 or $24 \mathrm{~h}$ with 17-AAG (250 nM). Mean \pm s.e.m., $n=3,{ }^{\star} P<0.05,{ }^{* *} P<0.01$. PAGE, polyacrylamide gel electrophoresis; TATA-BP, TATA-binding protein control. 
$1 \mathrm{~cm}$ sections in phosphate-buffered saline containing $15 \mathrm{~mm}$ HEPES (4-(2-hydroxyethyl)-1-piperazineethanesulfonic acid) and $1 \mathrm{~mm}$ EDTA with vigorous agitation on a vortex mixer. The tissue was then passed through a $70-\mu \mathrm{m}$ tissue strainer, and the process repeated until the wash remained clear. The remaining lamina propria (LP) was digested in $1 \mathrm{mg} \mathrm{ml}^{-1}$ Collagenase Type VIII (Sigma Aldrich, St. Louis, MO, C9722) for $10 \mathrm{~min}$ in an orbital shaker at 270 r.p.m. and $37^{\circ} \mathrm{C}$. Tissues were vortexed briefly and filtered to remove any remaining undigested material and cells counted before flow cytometric evaluation.

Cytokine production assays. Tissue explants $\left(0.5 \mathrm{~cm}^{2}\right)$ were cultured for $24 \mathrm{~h}$ in Dulbecco's modified Eagle's medium (without sodium pyruvate, Cellgro Manassas, VA, supplemented with $5 \%$ fetal bovine serum, $2 \mathrm{~mm}$ glutamine, $100 \mathrm{IU}$ penicillin and $100 \mathrm{\mu g} \mathrm{ml}^{-1}$ streptomycin; Invitrogen). Culture supernatants were then analyzed for the presence of cytokines using the Milliplex Cytokine Multiplex Assay system (Logan, UT).

Flow cytometry. Cells from indicated compartments were incubated with fluorescent rat anti-mouse antibodies, including against: mouse CD3 (17A2), CD4 (RM4-5), CD25 (PC61.5), HSP90 $\alpha$ (C-20), HSP90 $\beta$ (D-19), IL-10 (JES5-16E3), and Foxp3 (FJK16S) or their respective isotype controls. Foxp3 staining was performed according to the manufacturer's instructions (eBiosciences, San Diego, CA). Heat shock of cells was performed by incubating the cells for $30 \mathrm{~min}$ at $42^{\circ} \mathrm{C}$. Cells were stained, washed, and fixed with $2 \%$ paraformaldehyde and analyzed using the FACS Canto system (Becton-Dickinson Immunocytometry Systems, San José, CA). Post-analyses were performed using FlowJo software (Tree Star, Ashland, OR). Intracellular cytokine staining for IL-10 was performed as previously described. ${ }^{39}$

T-cell proliferation assays. $\mathrm{CD} 4{ }^{+} \mathrm{CD} 25^{+}$Tregs were isolated by negative selection of $\mathrm{CD} 4^{+} \mathrm{T}$ cells, followed by positive selection of $\mathrm{CD}^{+} 5^{+}$cells using the MACS Treg isolation kit (Miltenyi Biotec). Fifty-thousand CellTrace Violet-labeled (Invitrogen) $\mathrm{CD} 4{ }^{+} \mathrm{CD} 25^{\mathrm{Neg}}$ effector $\mathrm{T}$ cells per well were stimulated with anti-CD3 mAb in the presence of irradiated syngeneic allophycocyanin and varying ratios of purified $\mathrm{CD}_{4}{ }^{+} \mathrm{CD} 25^{+}$Treg from $\mathrm{HSF} 1^{+/+}, \mathrm{IL}-10^{-/-}$or HSF1 ${ }^{-1-}$ mice; suppression of proliferation was determined by the CellTrace profile by dividing effector cells at $72 \mathrm{~h}$.

In vitro stimulation assays. Freshly isolated $\mathrm{CD} 4{ }^{+} / \mathrm{CD} 25^{+}$Tregs from wild-type mice were stimulated with plate-bound anti-CD3 antibody $\left(2 \mu \mathrm{g} \mathrm{ml}^{-1}\right.$; eBioscience) and soluble anti-CD28 $\left(2 \mu \mathrm{g} \mathrm{ml}^{-1}\right.$; eBioscience) with (out) 17-AAG (250 nm) for either 6 or $24 \mathrm{~h}$. Nuclear and cytoplasmic protein extracts were isolated after $6 \mathrm{~h}$ using the NEPER extraction kit (Thermo Scientific, Rockford, IL) according to the manufacturer's instructions. Western blot of HSF1 (4356S, Cell Signaling) using both denaturing and non-denaturing conditions were performed on $4-15 \%$ gradient gels (Biorad, Hercules, CA). RNA was isolated from both timepoints using the RNeasy kit (Qiagen, Valencia, CA) before cDNA synthesis and realtime RT-PCR (Taqman Probes, Life Technologies, Grand Island, NY). Individual wells were internally controlled by multiplexing with VIC-labeled $18 \mathrm{~S}$ Taqman probe.

Statistics. Statistical analyses were performed using Student's $t$-test or repeated measures analysis of variance with Graphpad Prism Data Analysis software (GraphPad Software, La Jolla, CA). Data were expressed as mean \pm s.e.m. Statistical significance was set at $P<0.05$.

SUPPLEMENTARY MATERIAL is linked to the online version of the paper at http://www.nature.com/mi

\section{ACKNOWLEDGEMENTS}

Grant support: K08DK080189 (EDZ) and CCFA-2652 (CBC) and UL1 RR025780 (EDZ and CBC).

\section{AUTHOR CONTRIBUTION}

All authors contributed to the generation of data, editing, and proofing of this manuscript.

\section{DISCLOSURE}

The authors declared no conflict of interest.

c 2013 Society for Mucosal Immunology

\section{REFERENCES}

1. Singh, B. et al. Control of intestinal inflammation by regulatory $T$ cells. Immunol. Rev. 182, 190-200 (2001).

2. Mottet, C., Uhlig, H.H. \& Powrie, F. Cutting edge: cure of colitis by CD4 + CD25 + regulatory T cells. J. Immunol. 170, 3939-3943 (2003).

3. Duchmann, R. et al. Tolerance exists towards resident intestinal flora but is broken in active inflammatory bowel disease (IBD). Clin. Exp. Immunol. 102, 448-455 (1995).

4. de Zoeten, E.F. et al. Histone deacetylase 6 and heat shock protein 90 control the functions of foxp3+ T-regulatory cells. Mol. Cell. Biol. 31, 2066-2078 (2011).

5. De, A.K., Kodys, K.M., Yeh, B.S. \& Miller-Graziano, C. Exaggerated human monocyte IL-10 concomitant to minimal TNF-alpha induction by heatshock protein 27 (Hsp27) suggests Hsp27 is primarily an antiinflammatory stimulus. J. Immunol. 165, 3951-3958 (2000).

6. Chatterjee, A. et al. Heat shock protein 90 inhibitors prolong survival, attenuate inflammation, and reduce lung injury in murine sepsis. Am. J. Respir. Crit. Care Med. 176, 667-675 (2007)

7. Xie, Y., Chen, C., Stevenson, M.A., Auron, P.E. \& Calderwood, S.K. Heat shock factor 1 represses transcription of the IL-1beta gene through physical interaction with the nuclear factor of interleukin 6. J. Biol. Chem. 277, 11802-11810 (2002).

8. Luo, $X$. et al. Release of heat shock protein 70 and the effects of extracellular heat shock protein 70 on the production of IL10 in fibroblast-like synoviocytes. Cell Stress Chaperones 13, 365-373 (2008).

9. Xie, Y., Cahill, C.M., Asea, A., Auron, P.E. \& Calderwood, S.K. Heat shock proteins and regulation of cytokine expression. Infect. Dis. Obstet. Gynecol. 7, 26-30 (1999).

10. Nam, S.Y. et al. Heat shock protein gene 70-2 polymorphism is differentially associated with the clinical phenotypes of ulcerative colitis and Crohn's disease. J. Gastroenterol. Hepatol. 22, 1032-1038 (2007).

11. Tanaka, K. et al. Genetic evidence for a protective role for heat shock factor 1 and heat shock protein 70 against colitis. J. Biol. Chem. 282 23240-23252 (2007).

12. Zou, J., Guo, Y., Guettouche, T., Smith, D.F. \& Voellmy, R. Repression of heat shock transcription factor HSF1 activation by HSP90 (HSP90 complex) that forms a stress-sensitive complex with HSF1. Cell 94, 471-480 (1998).

13. Bagatell, R. et al. Induction of a heat shock factor 1-dependent stress response alters the cytotoxic activity of hsp90-binding agents. Clin. Cancer Res. 6, 3312-3318 (2000).

14. Prakken, B.J. et al. Induction of IL-10 and inhibition of experimental arthritis are specific features of microbial heat shock proteins that are absent for other evolutionarily conserved immunodominant proteins. J. Immunol. 167, 4147-4153 (2001).

15. Poulaki, V. et al. Inhibition of Hsp90 attenuates inflammation in endotoxininduced uveitis. FASEB J. 21, 2113-2123 (2007)

16. Dello Russo, C. et al. The heat-shock protein 90 inhibitor 17 -allylamino17-demethoxygeldanamycin suppresses glial inflammatory responses and ameliorates experimental autoimmune encephalomyelitis. J. Neurochem. 99, 1351-1362 (2006).

17. Marcu, M.G., Chadli, A., Bouhouche, I., Catelli, M. \& Neckers, L.M. The heat shock protein 90 antagonist novobiocin interacts with a previously unrecognized ATP-binding domain in the carboxyl terminus of the chaperone. J. Biol. Chem. 275, 37181-37186 (2000).

18. Tomasello, G. et al. Hsp10, Hsp70, and Hsp90 immunohistochemical levels change in ulcerative colitis after therapy. Eur. J. Histochem. 55, e38 (2011). 
19. Pratt, W.B. The hsp90-based chaperone system: involvement in signal transduction from a variety of hormone and growth factor receptors. Proc. Soc. Exp. Biol. Med. 217, 420-434 (1998).

20. Powrie, F., Correa-Oliveira, R., Mauze, S. \& Coffman, R.L. Regulatory interactions between CD45RBhigh and CD45RBlow CD4 $+\mathrm{T}$ cells are important for the balance between protective and pathogenic cell-mediated immunity. J. Exp. Med. 179, 589-600 (1994).

21. Asseman, C. \& Powrie, F. Interleukin 10 is a growth factor for a population of regulatory T cells. Gut 42, 157-158 (1998).

22. Asseman, C., Mauze, S., Leach, M.W., Coffman, R.L. \& Powrie, F. An essential role for interleukin 10 in the function of regulatory T cells that inhibit intestinal inflammation. J. Exp. Med. 190, 995-1004 (1999).

23. Collins, C.B. et al. Flt3 ligand expands CD103(+) dendritic cells and FoxP3(+) T regulatory cells, and attenuates Crohn's-like murine ileitis. Gut 61, 1154-1162 (2012).

24. Pratt, W.B. \& Toft, D.O. Regulation of signaling protein function and trafficking by the hsp90/hsp70-based chaperone machinery. Exp. Biol. Med. (Maywood) 228, 111-133 (2003).

25. Wieten, L. et al. IL-10 is critically involved in mycobacterial HSP70 induced suppression of proteoglycan-induced arthritis. PLoS One 4 , e41862009)

26. Pimienta, G., Herbert, K.M. \& Regan, L. A compound that inhibits the HOPHsp90 complex formation and has unique killing effects in breast cancer cell lines. Mol. Pharm. 8, 2252-2261 (2011).

27. de Zoeten, E.F., Wang, L., Sai, H., Dillmann, W.H. \& Hancock, W.W. Inhibition of HDAC9 increases Tregulatory cell function and prevents colitis in mice. Gastroenterology 138, 583-594 (2010).

28. Fujikake, N. et al. Heat shock transcription factor 1-activating compounds suppress polyglutamine-induced neurodegeneration through induction of multiple molecular chaperones. J. Biol. Chem. 283, 26188-26197 (2008).
29. Otani, S. et al. Effect of preinduction of heat shock proteins on acetic acid-induced colitis in rats. Dig. Dis. Sci. 42, 833-846 (1997).

30. Boyault, C. et al. HDAC6 controls major cell response pathways to cytotoxic accumulation of protein aggregates. Genes Dev. 21, 2172-2181 (2007).

31. Zhang, $\mathrm{H}$. et al. HSF1 is a Transcriptional Activator of IL-10 Gene Expression in RAW264.7 Macrophages. Inflammation 35, 1558-1566 (2012).

32. Suemasu, S. et al. A role for HSP70 in protecting against indomethacininduced gastric lesions. J. Biol. Chem. 284, 19705-19715 (2009).

33. Housby, J.N. et al. Non-steroidal anti-inflammatory drugs inhibit the expression of cytokines and induce HSP70 in human monocytes. Cytokine 11, 347-358 (1999).

34. Wang, X. et al. Phosphorylation of HSF1 by MAPK-activated protein kinase 2 on serine 121, inhibits transcriptional activity and promotes HSP90 binding. J. Biol. Chem. 281, 782-791 (2006).

35. Chen, X.S. et al. Diverse effects of Stat 1 on the regulation of hsp90alpha gene under heat shock. J. Cell. Biochem. 102, 1059-1066 (2007).

36. Yun, T.J. et al. EC144, a synthetic inhibitor of heat shock protein 90 , blocks innate and adaptive immune responses in models of inflammation and autoimmunity. J. Immunol. 186, 563-575 (2011).

37. Zhang, Y. et al. Mice lacking histone deacetylase 6 have hyperacetylated tubulin but are viable and develop normally. Mol. Cell. Biol. 28, 1688-1701 (2008).

38. Smith, P. et al. Infection with a helminth parasite prevents experimental colitis via a macrophage-mediated mechanism. J. Immunol. 178, 4557-4566 (2007).

39. Collins, C.B. et al. Retinoic acid attenuates ileitis by restoring the balance between T-helper 17 and T regulatory cells. Gastroenterology 141, 1821-1831 (2011). 